\title{
THE EFFECT OF DIFFERENT MOISTURE AND LIGHT REGIMES ON PRODUCTIVITY, LIGHT INTERCEPTION AND USE EFFICIENCY OF COMMON BEAN
}

\author{
Walelign Worku ${ }^{1}$ and Arne O. Skjelvåg ${ }^{2}$ \\ ${ }^{1}$ University of Hawassa, Awassa College of Agriculture PO Box 5, Awassa, \\ Sidamo, Ethiopia. E-mail: walelignworku@yahoo.co.uk \\ ${ }^{2}$ Norwegian University of Life Sciences, Department of Plant and Environmental Sciences
}

\begin{abstract}
The response of common bean (Phaseolus vulgaris L.) to different moisture.and light regimes was examined in a $5 \times 2$ factorial field experiment in Ethiopia. The soil moisture levels were: (1) well watered throughout (2) stress during the vegetative phase (3) stress during the flowering phase (4) stress during the seed filling phase and (5) stress throughout. The two light levels were: (1) full light and (2) $50 \%$ shade. The highest seed yield loss due to water stress was observed for the seed filling phase followed by the flowering and vegetative phases. There were significant interactions between moisture availability and light intensity for seed yield. Shading reduced seed yield under full water supply or early drought while it increased it under terminal and season-long drought. Seed yield was significantly correlated to pod number per plant, under both light regimes. Plants under full light produced $34 \%$ less pods on the main stem but $158 \%$ more on the branches compared to shaded plants. Water use efficiency was significantly decreased by water stress while shading increased it. The lowest total leaf area duration and total light interception occurred from water stress during seed filling. Water stress reduced radiation use efficiency (RUE) by $33 \%$ while shading increased it by $27 \%$. Under full light, total intercepted PAR and RUE accounted for $90 \%$ of the variation in seed yield while it is $83 \%$ in the shade. Light intercepted during seed filling contributed $56 \%$ and $33 \%$. of the explained variation in seed yield under full light and shade, respectively.
\end{abstract}

\section{Key words/phrases: Light interception, Phaseolus vulgaris, radiation use efficiency, seed yield, shading}

\section{INTRODUCTION}

Water stress and reduced level of light under intercropping are important limiting factors for common bean production in the majority of production areas. Sixty percent of common bean production in the world is grown under water stress making drought the second largest contributor to yield reduction after disease (Singh, 1995). On the other hand, when common bean is grown as an under storey component crop, one of the direct effects is that it receives a reduced supply of radiation energy. The poorer performance of legumes when intercropped may be partly because the quantity of light reaching their canopy is reduced by their taller companion crop (Stirling et al., 1990).

The amount of dry matter produced by a crop depends on the amount of intercepted solar radiation and the efficiency with which it is converted to dry matter (Gifford et al., 1984; Squire, 1990). Under sub-optimal moisture supply a reduction in dry matter production may occur because of reduced light interception as a result of accelerated leaf senescence (De Souza et al., 1997), smaller leaf size, lower rates of leaf initiation and branching (Squire, 1990). Moreover, reduction in radiation use efficiency (RUE) is also a contributing factor. For instance, reductions in RUE under water stress conditions have been reported in five-grain legumes (Muchow, 1985), in barley (Jamieson et al., 1995) and in pigeon pea (Nam et al., 1998). The economic yield is further influenced by the way the plant distributes its assimilates to the various sinks.

Intercropping with maize is the dominant form of production for common bean in Africa (Wortmann et al., 1998). In. Ethiopia, common bean is mainly grown intercropped with various components in different parts of the country (Asfaw Negassa and Abubaker Mussa, 1990; Shimelis W/Hawariat et, al., 1990; Tenaw Workayehu and Yeshi Chiche, 1990). Field shading studies involving different moisture levels may help better understand the mechanisms of intercropping for an effective manipulation of the system. The effects of water stress on common bean are well documented. However, there is only 
a limited number of studies made to examine the relative importance of light intensity and moisture availability in "relation to productivity, radiation interception and use efficiency under combined moisture and light regimes. In a field shading study, which excluded 50 and $30 \%$ of photosynthetically active radiation (PAR), Campbell et al. (1969) found an increase in RUE under shading in wheat. He also reported that in dry years yield was higher under the $30 \%$ shade while $50 \%$ shade always. resulted in yield reduction. Similarly, Stirling et al. (1990) observed increased RUE in groundnut, which was grown under $46 \%$ shade, though final yield was reduced.

Investigation of the response of plants to water stress under variable light conditions has its complications. , Rate of evapotranspiration is largely dependent on the amount of solar radiation input for a given plant. Depending on its intensity, shading reduces the energy load on the leaves and bare soil that iwill be available to drive evapotranspiration. This would cause differences in the rate of withdrawal of plant available soil water. The result will be that the soil under shade will dry slowly and hence it will not match its unshaded counterpart with respect to the level of water stress. If equal stress is achieved, it will be at different periods leading to a discrepancy in developmental phase. Such conditions complicate investigations aimed at observing combined effects of water stress with shading.

The purpose of the present experiment was to examine effects on productivity, light interception and use efficiency on common bean when it is subjected to different levels of moisture at various developmental phases under different light regimes.

\section{MATERIALLS AND METHODS}

This experiment was carried out during the offseason in Southern Ethiopia at Awassa. Awassa is located $7^{\circ} 5^{\prime} \mathrm{N}$ and $38^{\circ} 30^{\prime} \mathrm{E}$ at 1660 meters a.s.l. The research site was at the Farm and Research Centre of the Awassa College of Agriculture, University of Hawassa. The cultivar Red Wolaita was used, a popular indeterminate cultivar from southern Ethiopia with a medium seed size.

Planting was done on 27 November 1999 and the experiment conducted during the 1999/2000 offseason. Before sowing, soil samples to a depth of $30 \mathrm{~cm}$ were taken for texture and organic matter analyses. The soil has a loam texture consisting of
$47 \%$ sand, $37 \%$ silt, $16 \%$ clay and $5 \%$ organic matter. The $\mathrm{pH}$ of the soil was 7.7. Two seeds per hill were hand sown at a spacing of $40 \mathrm{~cm} \times 10 \mathrm{~cm}$ on the sides of the ridges. Thinning was done five days after emergence to allow a density of 25 plants $\mathrm{m}^{-2}$. A pre-sowing application of diammonium phosphate, containing 18:46:0 \% of NPK, at a rate of $20 \mathrm{~kg} \mathrm{P} \mathrm{ha-1}$ was carried out. Weeds were controlled by hand weeding as often as required and this was carried out uniformly across all plots. A shallow cultivation was carried out 23 days after emergence.

\section{Design and treatments}

Treatments were selected from a factorial combination of soil moisture and light intensity. There were five moisture levels: 1 . Well watered at all growth phases (WWW), 2. Water stress during the vegetative phase (DWW), 3 . Water stress during the flowering phase (WDW), 4. Water stress during the seed filling phase (WWD), and 5. Water stress throughout (DDD). The light factor had two' levels: 1. Full incident natural light $(\mathrm{F})$ and 2. Shade, which was $50 \%$ of full light (S). Moisture and light were used as main and sub plot factors, respectively, in a split plot design with three replications. Each sub plot consisted of seven rows, each $2.5 \mathrm{~m}$ long and spaced $0.4 \mathrm{~m}$ apart. Based on the texture and organic matter parameters the soil moisture holding capacity was determined using a multiple regression equation (Pidgeon, 1972).

\section{Water management}

Well watered (W) treatments were kept above $75 \%$ (vol/vol) of plant available soil water, while the corresponding dry (D) treatments were allowed to fall to $10 \%$ (vol/vol) before irrigation was applied. Manually operated rain out shelters that could be taken on and off protected dry treatiments during the rare occasions of precipitation. Watering was provided from an irrigation main gated pipeline. One main canal running in front of each block, $1.5 \mathrm{~m}$ away from the plot line, supplied water to the plots by furrow irrigation. The water stress treatment was started five days after emergence. Soil moisture content of the top $15 \mathrm{~cm}$ was monitored at 3-4 days interval by a portable Time Domain Reflectometry apparatus (TRIMEsytem, IMKO GMBH, Germany). At the end of each drying cycle, plots were irrigated and restored to field capacity. The time of rewatering for the dry main plot treatments was determined on soil' moisture readings of the open treatment. Plots. under the shade did not reach the same level of 
water stress as those of the open treatments (Fig. 1). This option was chosen partly to keep irrigation on the main plots and partly to observe shading effect on moisture status of the soil and its consequences. However, these conditions inevitably introduced some confounding of light and water effects. Thus, the effect of light was estimated from a separate analysis of the data under well-watered conditions differing only in light level. A separate analysis for each light level indicated that principally the water stress effect has shown a similar trend in both light regimes. The lesser effect of water stress observed under shade was mainly due to the fact that the magnitude of stress was low. As a result, the effects of moisture and its interaction with light were tested using the data from the entire treatments.

The entire life cycle of the plants was divided as follows. Vegetative; from emergence to first flower production by $50 \%$ of the plants. Flowering; from commencement of flowering to first appearance of pod at full length by $50 \%$ of the plants. Seed filling; start of full-length pods to physiological maturity. Physiological maturity was reached when the first pods by $50 \%$ of the plants turned black and loose to touch. The durations, taking the overall averages, were 43,18 and 27 for the vegetative, flowering and seed filling phases, respectively. As an indeterminate cultivar, flowering and pod set occurred partly together.

\section{Light}

The light intensity treatments were provided by covering plots with a white (neutral) cotton gauze cloth, which intercepted about $50 \%$ of insulation at a distance of one meter. The shades were supported on four wooden frames located $15 \mathrm{~cm}$ away from each corner of the plot and were connected at the top. The height of the shade was $175 \mathrm{~cm}$ in order to allow a good circulation of air. To avoid entry of light at the sides, three sides of each plot were covered with shade, cloth leaving the bottom $20 \mathrm{~cm}$ open. The northern side was fully open. The shades were placed two days after emergence and were left until harvesting. Plots were arranged in the east-west direction so that shading of open treatments could be avoided. To avoid shading of neighbouring blocks, a distance of adequate length was kept between blocks.

\section{Weather and water use}

Current weather and climate records were obtained from a nearby research station located about one $\mathrm{km}$ from the site (Table 1). Both potential and actual crop evapotranspiration were calculated using the FAO Penman-Monteith equation (Allen et al., 1998) by using monthly mean weather data (Table 2 and Fig. 1). Vapour pressure deficits were estimated from diurnal mean temperature and relative humidity data.
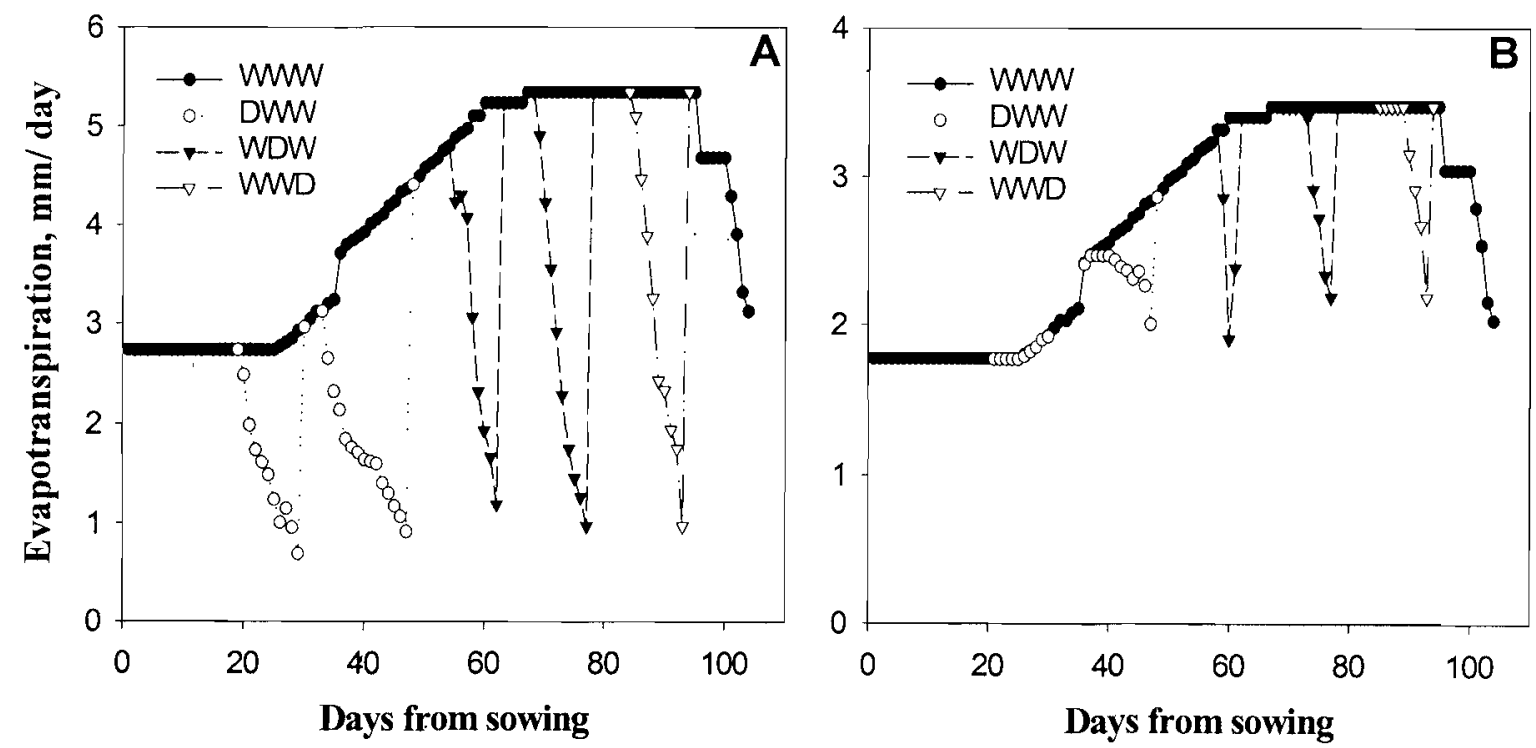

Fig. 1. Daily water use pattern of the various treatments during the $1990 / 00$ off-season at Awassa under (A) full light and (B) shade. 
Table 1. Seasonal and ten year averages (temperature and radiation) of monthly mean weather records of the experimental site at Awassa during off-season.

\begin{tabular}{|c|c|c|c|c|c|c|c|c|}
\hline \multirow{3}{*}{ Month } & \multirow{3}{*}{$\begin{array}{l}\text { Rainfall } \\
\text { (mm) } \\
1999 / 00\end{array}$} & \multicolumn{4}{|c|}{ Air temperature, ${ }^{\circ} \mathrm{C}$} & \multirow{2}{*}{\multicolumn{2}{|c|}{ Radiation (MJ $\mathrm{m}^{-2}$ day $\left.^{-1}\right)$}} & \multirow{3}{*}{$\begin{array}{l}\mathrm{VPD}(\mathrm{kPa}) \\
1999 / 00\end{array}$} \\
\hline & & \multicolumn{2}{|c|}{ Minimum } & \multicolumn{2}{|c|}{ Maximum } & & & \\
\hline & & $1999 \% 00$ & $1990-99$ & $1999 / 00$ & $1990-99$ & $1999 / 00$ & 1990-99 & \\
\hline Nov. & 21.3 & 9.9 & 10.4 & 27.3 & 27.5 & 17.0 & 16.9 & 1.06 \\
\hline Dec. & 2.4 & 10.2 & 10.3 & 28.8 & 28.0 & 20.2 & 17.2 & 1.24 \\
\hline Jan. & 0.0 & 10.3 & 11.3 & 29.4 & 28.3 & 19.4 & 16.5 & 1.36 \\
\hline Feb. & 0.0 & 10.9 & 12.4 & 30.7 & 29.1 & 19.9 & 16.7 & 1.54 \\
\hline Mar. & 6.5 & 12.5 & 13.0 & 31.9 & 29.3 & 18.2 & 16.1 & 1.25 \\
\hline
\end{tabular}

VDP, mean diurnal vapour pressure deficit; crop growth period was 27 Nov 1999-11 March 2000.

Table 2. Cumulative water use $(\mathrm{mm})$ from emergence to maturity, duration (days) and number of drying cycles during vegetative (DWW), flowering (WDW), seed filling (WWD) and all three (DDD) phases.

\begin{tabular}{llllll}
\hline $\begin{array}{l}\text { Moisture } \\
\text { regime }\end{array}$ & \multicolumn{2}{l}{ Cumulative water use $(\mathrm{mm})$} & $\begin{array}{l}\text { Duration } \\
\text { (days) }\end{array}$ & $\begin{array}{l}\text { No. of drying } \\
\text { cycles }\end{array}$ & $\begin{array}{l}\text { No. of } \\
\text { days/cycle }\end{array}$ \\
\cline { 2 - 5 } & $\mathrm{F}$ & $\mathrm{S}$ & 0 & 0.0 & 0.0 \\
WWW & 406 & 270 & 33 & 2.0 & 16.5 \\
DWW & 361 & 257 & 28 & 2.0 & 14.0 \\
WDW & 358 & 252 & 22 & 1.3 & 16.0 \\
WWD & 365 & 254 & 81 & 5.2 & 15.6 \\
DDD & 272 & 236 & & \\
\hline
\end{tabular}

F, full light; S, shaded to $50 \%$ of full light

Several on the spot measurements of temperature and relative humidity were made during daytime to compare the microclimate under the shade with that of the open. On the average the daytime air temperature under the shade was found to be higher by $1.0-1.5^{\circ} \mathrm{C}$ while no appreciable difference was detected in relative humidity. For the wet treatment regime, it was assumed that the irrigation has met the potential evapotranspiration requirement. The crop coefficients $(\mathrm{Kc})$ of the FAO Penaman-Monteith equation used were 0.7 for the initial, 1.2 for the mid season and 0.6 for the late season phases, taking into account the required modifications (Allen et al., 1998). The initial phase was from sowing to 15 days after emergence (DAE), the development phase was from 15 to $50 \mathrm{DAE}$, the mid season phase was from $50 \mathrm{DAE}$ to physiological maturity and the late season was from physiological maturity to harvesting. For water stress treatments, $\mathrm{Kc}$ was modified by a water stress coefficient $(\mathrm{Ks})$ varying between 1 and 0 . The average fraction of plant available soil moisture (threshold deficit value) that can be depleted $(\mathrm{P})$ before water stress occurs was set to 0.45 (Allen et al., 1998). Water use efficiency (WUE) and Evapotranspiration efficiency (ETE) were estimated by dividing seed yield and total dry matter by cumulative water used, respectively (Ehdaie and Waines, 1993).

\section{Data collection and analysis}

Four plants were harvested from each plot every fortnight between emergence and physiological maturity except the last one, which was taken after a 12-day interval. The two outermost rows were kept as border rows. Above ground parts of four plants were harvested from each plot. During the vegetative phase, plant material was separated into leaf, stem and branch stems. During the flowering and the seed filling phases, samples were partitioned into leaf, stem, branch stems and reproductive parts (flower bud + flower + pod): At each sampling green leaf area was measured with an MK2 area meter (Delta-T-Devices, Cambridge, England). Senescent and dead leaves were included in shoot dry matter.determination. Dry weights of all samples were determined after oven drying at $70^{\circ} \mathrm{C}$ to constant weight.

Grain yield and final above ground dry matter was determined from the final harvest made on the two centre rows with an area of $1.6 \mathrm{~m}^{2}(2 \mathrm{~m} \times 0.8$ $\mathrm{m})$. Harvesting was conducted when at least $50 \%$ of the pods on each plant were dry to touch. After harvest, all plants from each replication were placed inside nylon bags and hung up for further 
drying before threshing. Pod number per plant and number of seeds per pod were determined from four plants from each replication.

Leaf are duration (LAD) for the interval between the consecutive samplings was calculated by taking the mean leaf area index between the two samplings and multiplying it by the number of days between samplings. Total LAD was calculated by summing the $\mathrm{LAD}$ of the individual samplings (Nam et al., 1998).

Total $L A D=\sum_{n}\left[\left(\operatorname{LAI}_{n-1}+L A I_{n}\right) / 2\right]\left(t_{n}-t_{n-1}\right)$, where:

$\mathrm{LAI}_{n}$ is LAI at sampling time $\mathbf{t}_{\mathbf{n}}$ $\mathrm{LAI}_{n-1}$ is LAI at sampling time $t_{n-1}$.

RUE was estimated as the first derivative of regressed accumulated dry matter on cumulative intercepted radiation. Cumulative intercepted PAR was calculated by:

$$
\sum_{i=1}^{n} \operatorname{IPAR}_{\mathrm{i}}=\sum_{i=1}^{n} \mathrm{Qg}_{\mathrm{i}}{ }^{*} 0.5\left(1-\exp \left(-\mathrm{k}^{*} \mathrm{LAI}_{\mathrm{i}}\right)\right)
$$

where:

$$
\begin{aligned}
\mathrm{Qg}= & \text { mean recorded short wave radiation } \\
& \text { above the plant stand } \\
0.5= & \text { photosynthetically active radiation } \\
& \text { fraction of } \mathrm{Qg} \text { (Monteith, 1972) } \\
\mathrm{k}= & 0.8, \text { extinction coefficient } \\
\mathrm{LAI}= & \text { leaf area index estimated from } \\
& \text { sequential samplings } \\
\mathrm{I} \quad & \text { day number from emergence to } 82 \text { days } \\
& \text { thereafter } \\
\mathrm{IPAR}= & \text { intercepted photosynthetically active } \\
& \text { radiation }
\end{aligned}
$$

Data were analysed using the General Linear Model of SAS (release 6.12). Mean separation for main effects were obtained by Fisher's least significant difference (LSD) test.

\section{RESULTS}

\section{Productivity and related parameters}

Seed Yield: Yield was significantly reduced by drought and increasingly so when imposed in later phases (Table 3). Shading alsa reduced seed yield significantly. There was a significant interaction between moisture and light regimes. Shading

\begin{tabular}{|c|c|c|c|c|c|c|c|c|c|}
\hline Treatment & $\begin{array}{l}\text { Yield a } \\
\left(\mathrm{g} \mathrm{m}^{-2}\right)\end{array}$ & $\begin{array}{l}\text { Pods/ } \\
\text { plant }\end{array}$ & $\begin{array}{l}\text { Pods on } \\
\text { main stem }\end{array}$ & $\begin{array}{l}\text { Pods on } \\
\text { branches }\end{array}$ & $\begin{array}{l}\text { Seeds/ } \\
\text { pod }\end{array}$ & $\begin{array}{l}\text { Seed } \\
\text { weight (g) }\end{array}$ & $\begin{array}{l}\text { WUE } \\
\left(\mathrm{g} \mathrm{kg}^{-1}\right)\end{array}$ & $\begin{array}{l}\mathrm{ETE}^{\mathrm{c}} \\
\left(\mathrm{g} \mathrm{kg}^{-1}\right)\end{array}$ & $\begin{array}{l}\text { Maturity period } \\
\text { (days) }\end{array}$ \\
\hline \multicolumn{10}{|l|}{ Moisture } \\
\hline WWW & $352 a$ & $14.9 \mathrm{a}$ & $3.6 \mathrm{a}$ & $11.3 \mathrm{a}$ & $5.3 a$ & $19.4 a$ & $0.88 \mathrm{a}$ & $1.91 \mathrm{a}$ & $93.3 a$ \\
\hline DWW & $312 b$ & $13.9 \mathrm{ab}$ & $4.8 \mathrm{a}$ & $9.0 \mathrm{ab}$ & $4.8 \mathrm{a}$ & $18.5 \mathrm{a}$ & $0.82 \mathrm{a}$ & $1.84 \mathrm{ab}$ & $93.8 \mathrm{a}$ \\
\hline WDW & $266 c$ & $12.5 \mathrm{ab}$ & $3.6 \mathrm{a}$ & $8.8 \mathrm{~b}$ & $4.8 \mathrm{a}$ & $19.8 \mathrm{a}$ & $0.73 b$ & $1.71 \mathrm{c}$ & $92.0 \mathrm{a}$ \\
\hline WWD & $248 \mathrm{~d}$ & $11.8 \mathrm{bc}$ & $3.6 a$ & $8.2 b c$ & $5.1 \mathrm{a}$ & $17.9 \mathrm{a}$ & $0.69 \mathrm{~b}$ & $1.65 \mathrm{~cd}$ & $90.5 b$ \\
\hline DDD & $197 \mathrm{e}$ & $9.7 \mathrm{c}$ & $3.8 \mathrm{a}$ & $6.0 \mathrm{c}$ & $4.7 \mathrm{a}$ & $18.8 \mathrm{a}$ & $0.65 b$ & $1.57 \mathrm{~d}$ & $88.1 \mathrm{c}$ \\
\hline \multicolumn{10}{|l|}{ Light } \\
\hline $\mathrm{F}$ & $383 a$ & $19.1 \mathrm{a}$ & $2.9 a$ & $16.3 a$ & $4.9 \mathrm{a}$ & $18.1 \mathrm{~b}$ & $0.76 \mathrm{~b}$ & $1.69 \mathrm{~b}$ & $94.0 \mathrm{a}$ \\
\hline$S$ & $322 b$ & $10.7 \mathrm{~b}$ & $4.4 \mathrm{a}$ & $6.3 b$ & $5.6 \mathrm{a}$ & $20.8 \mathrm{a}$ & $1.00 \mathrm{a}$ & $1.78 \mathrm{a}$ & $92.0 \mathrm{a}$ \\
\hline \multicolumn{10}{|c|}{ Moisture $x$ Light } \\
\hline $\mathrm{P}$ & 0.004 & 0.106 & 0.331 & 0.270 & 0.112 & 0.003 & 0.116 & 0.619 & 0.279 \\
\hline
\end{tabular}
reduced yield under full water supply or early drought while it increased it under terminal and season long drought (Fig. 2).

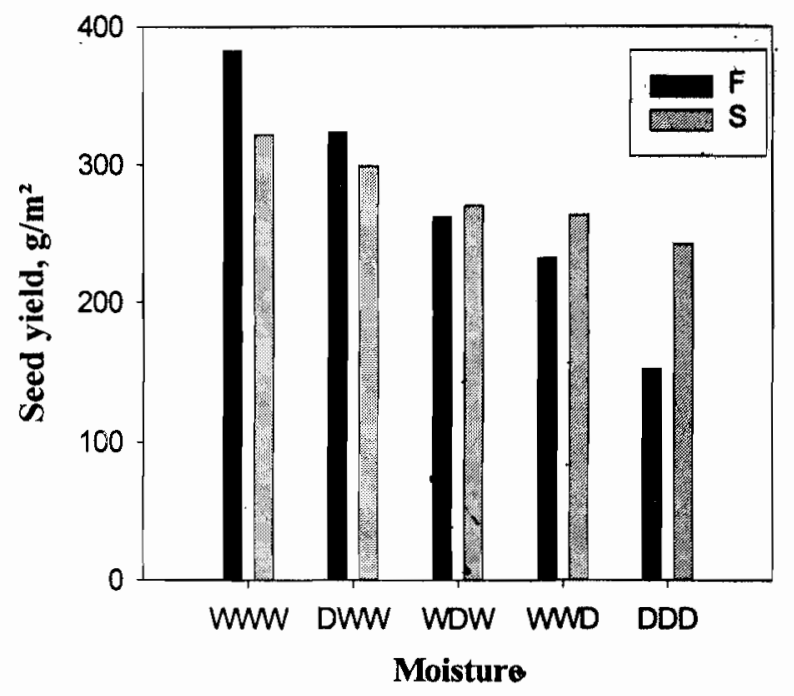

Fig. 2. Seed yield at full and reduced light intensity after introducing soil water stress (D) during the vegetative (DWW), flowering (WDW) and seed filling (WWD) phases, as well as drought and sufficient supply throughout. F, full; $S$, shade.

Table 3. Effects of moisture availability and light intensity on seed yield, yield components, water use efficiency (WUE), evapotranspiration efficiency (ETE) and duration of maturity period. 
Pod number per plant: Season long and terminal water stress caused a significant reduction in pod number per plant (Table 3). This was primarily due to pod number on branches while the number of pods on the main stem was not affected by water stress. Plants under the full light produced $78 \%$ more pods than shaded plants. Light level influenced the number of pods on the main stem and on the branches differently. There were $34 \%$ fewer pods on the main stem under full light compared to shaded plants. Contrary to this, unshaded plants produced $158 \%$ more pods on their branches. This was consistent with the difference in number of branches produced between the two light levels (data not shown).

Seed number per pod: Seed number per pod was not significantly affected by water stress and shading (Table 3). Shaded plants had more seeds per pod, though non significant.

Seed weight: Plants under shade produced significantly larger seeds than plants in the open (Table 3). A'significant moisture $x$ light interaction showed that while the variation was minimum under the shade, clrought during flowering under full light increased seed weight and reduced it during seed filling. It was not only the grain yield but also the quality of seeds that was most affected from terminal stress under full light. Seeds were not well filled and had a poorly developed colour. On the other hand, there was no loss observed in physical quality aspects like size and colour due to shading.

A simple correlation coefficient was used to determine the relative importance of the various yield components in explaining the variation in seed yield. Under full light, the correlation coefficients were $r=0.80(P=0.001)$ for pod number per plant, $r=0.28(P=0.328)$ for seed number per pod and $\mathrm{r}=0.15(\mathrm{P}=0.595)$ for seed weight. Under the shade the values were $r=0.66(P=0.007)$ for pod number per plant, $r=0.26(\mathrm{P}=0.338)$ for seed number per pod and $r=0.39(P=0.146)$ for seed weight.

Water use efficiency: The all-wet treatment gave a water use efficiency (WUE) value of $0.88 \mathrm{~g}$ seed DM $\mathrm{kg}^{-1}$ water while the lowest was 0.65 for the all-dry treatment. Water stress during flowering and seed filling significantly reduced WUE. The magnitude of WUE under shade showed a significant improvement, by $31 \%$ compared to the unshaded. Evapotranspiration efficiency has shown a similar trend (Table 3).

Growth period: Water stress significantly reduced growth duration by facilitating maturity (Table 3). There was, however, no significant difference in growth duration due to light level, although treatments under the shade reached the $50 \%$ flowering stage 5-7 days earlier (data not shown).

\section{Leaf area duration and intercepted PAR}

Leaf area duration: Significant reductions in total leaf area duration (LAD) occurred when water stress was imposed during flowering and seed filling phases and for season long stress (Table 4). The largest reductions were for season long and terminal water stress. A comparison of contributions to total $\mathrm{LAD}$ during the vegetative, flowering and seed filling phases showed that only reductions associated with vegetative and seed filling phase water stress were significant. Recovery of plants from the early water stress was evident from comparison of the LAD contributions of the flowering and seed filling phases. Among the three phases, the impact on LAD due to terminal stress was higher than that of early stress, with terminal stress reducing LAD by $25 \%$ and early stress by $17 \%$.

Shading did not affect total LAD significantly (Table 4), although phasic contributions to total LAD were increased by shading during the vegetative phase $(34 \%)$ and reduced during seed filling $(36 \%)$. A significant interaction between moisture and light was shown for seed filling LAD contribution, indicating that the loss of LAD was more severe under full light.

Intercepted PAR: Water stress significantly reduced total intercepted photosynthetically active radiation (PAR) and contributions to intercepted PAR during the vegetative and seed filling phases (Table 4). With respect to the total intercepted PAR, the treatments WWD and DDD intercepted less PAR, compared to the control. There were significantly reduced phasic contributions in intercepted PAR as a result of water stress during the vegetative and 
seed filling phases. The variation in intercepted PAR during flowering was minimal. Shading reduced total intercepted PAR and intercepted PAR during the three developmental phases.

\section{Radiation use efficiency}

A slightly better but a significant fit was found with a curvilinear relationship between dry matter production and intercepted PAR for the two moisture and light regimes (Fig. 3). Since none of the intercepts of the regression lines was significantly different from zero, for a uniform comparison all the regressions were recalculated and forced to pass through the origin. Radiation use efficiency (RUE), the first derivative of the regression equation of biomass accumulation as a function of intercepted PAR, was decreased by water stress while it was increased by shading

Table 4. Effects of moisture availability and light intensity on leaf area duration (LAD) and intercepted photosynthetically active radiation (IPAR).

\begin{tabular}{|c|c|c|c|c|c|c|c|c|}
\hline Treatment & $\begin{array}{l}\mathrm{LAD} / \text { total } \\
\text { (days) }\end{array}$ & $\begin{array}{l}\text { LAD/ } \\
\text { vegetative }\end{array}$ & $\begin{array}{l}\text { LAD/ } \\
\text { flowering }\end{array}$ & $\begin{array}{l}\text { LAD/ } \\
\text { sced filling }\end{array}$ & $\begin{array}{l}\mathrm{IPAR} / \text { total } \\
\left(\mathrm{M} / \mathrm{m}^{-2}\right)\end{array}$ & $\begin{array}{l}\mathrm{IPAR} / \\
\text { vegetative }\end{array}$ & $\begin{array}{l}\text { IPAR/ } \\
\text { flowering }\end{array}$ & $\begin{array}{l}\text { IPAR/ } \\
\text { seed filling }\end{array}$ \\
\hline \multicolumn{9}{|l|}{ Moisture } \\
\hline WWW & $200 \mathrm{a}$ & $34 \mathrm{a}$ & $59 \mathrm{a}$ & $106 a b$ & $394 a$ & $106 a$ & $115 a$ & $170 \mathrm{a}$ \\
\hline LWW & $190 \mathrm{ab}$ & $28 b$ & $55 a b$ & $106 \mathrm{ab}$ & $374 a b$ & $96 b$ & $109 \mathrm{a}$ & $169 \mathrm{a}$ \\
\hline WDW & $184 \mathrm{bc}$ & $34 a$ & $54 a b$ & $95 b$ & $383 a b$ & $106 a$ & $113 a$ & $161 a b$ \\
\hline WWD & $174 c$ & $34 a$ & $59 a$ & 796 & $366 b$ & $106 a$ & $115 \mathrm{a}$ & $143 b$ \\
\hline DDP & $145 d$ & $28 \mathrm{~b}$ & $50 b$ & $66 c$ & $342 c$ & $96 b$ & $109 a$ & $137 \mathrm{C}$ \\
\hline \multicolumn{9}{|l|}{ Light } \\
\hline $\mathrm{F}$ & $220 \mathrm{a}$ & $29 \mathrm{~b}$ & $61 a$ & $129 \mathrm{a}$ & $525 a$ & $133 a$ & $154 a$ & $237 a$ \\
\hline$S$ & $181 \mathrm{a}$ & $39 a$ & $58 a$ & $83 b$ & $262 \mathrm{~b}$ & $80 b$ & $77 b$ & $104 b$ \\
\hline \multicolumn{9}{|c|}{ Moisture * Light } \\
\hline $\mathrm{P}$ & 0.181 & 0.999 & 0.807 & 0.037 & 0.815 & 0.597 & 0.699 & 0.554 \\
\hline
\end{tabular}

Means with same letter are not significantly different at $5 \%$ level

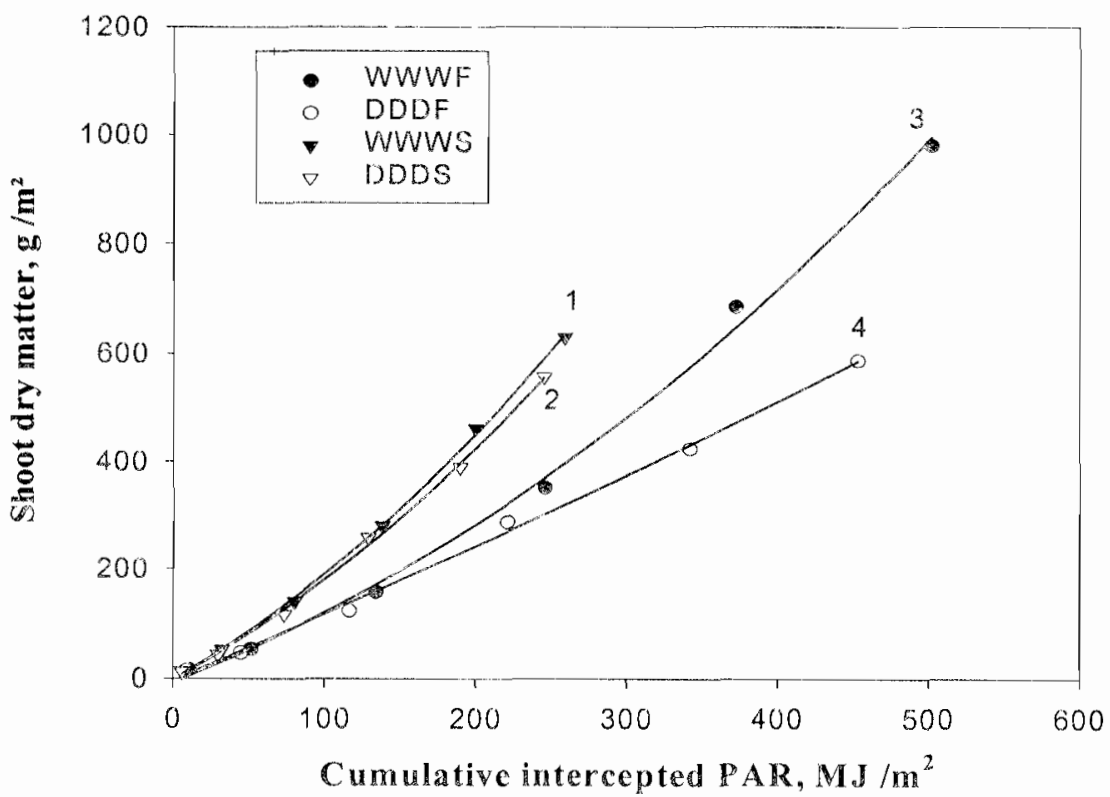

Fig. 3. Relationship between shoot dry matter and intercepted PAR $\mathrm{m}^{-2}$ land area, between emergence and 82 days thereafter, in wet (WWW) and dry (DDD) soil moisture regimes and at two light levels. F, full; $S$, shade. 
The values obtained under full light were 1.07$2.93 \mathrm{~g} \mathrm{DM} \mathrm{MJ}^{-1}$ PAR for well watered plants and 1.14-1.41 $\mathrm{g} \mathrm{DM} \mathrm{MJ}^{-1}$ PAR under the dry regime, showing a 33\% decline for the mean value due to water stress. Radration use efficiency values of 1.60-3.35 and 1.52:-3.05 $\mathrm{g} \mathrm{DM} \mathrm{MJ}^{-1}$ PAR were obtained under shading for the wet and dry moisture regimes, respectively. This showed a decline of only $7 \%$ for the mean value due to soil water stress, under shading. Mean RUE increased by $27 \%$ due to shading compared to full light treatments, under well-watered conditions. The increment was $75 \%$ for the same comparison under the dry soil moisture regime. An improved water status due to shading may have contributed to the increased RUE under the dry soil regime. Over all, shading averaged over moisture regimes caused a $47 \%$ increase in RUE.

\section{Relationship between seed yield, intercepted PAR, RUE and water stress}

Separate multiple regressions were computed for the two light regimes in order to examine the relationship between seed yield, total intercepted PAR, RUE and water stress (Table 5). Under full light, total intercepted PAR and RUE accounted for $90 \%$ of the variation in seed yield while water stress made a $4 \%$ contribution. In the shade, intercepted PAR and RUE accounted for all the explained variation of $83 \%$. The relationship was investigated further by including phasic components of the total intercepted PAR (Table 6). This isolated intercepted PAR during the seedfilling phase and over all RUE with major significant contributions under both light regimes. The contributions from intercepted PAR during the other phases were not significant under full light. However, intercepted PAR during the vegetative phase made a significant contribution under shade.

Table 5. Multiple regression of cumulative intercepted photosynthetically active radiation (IPAR), radiation use efficiency (RUE) and water deficit (WD) in relation to seed yield under different light levels.

\begin{tabular}{|c|c|c|c|c|c|c|}
\hline \multirow[b]{2}{*}{ Variable } & \multicolumn{3}{|c|}{ Full Light } & \multicolumn{3}{|c|}{ Shade } \\
\hline & $\begin{array}{l}\text { Parameter } \\
\text { Estimate }\end{array}$ & Partial $R^{2}$ ' & $P$ & $\begin{array}{c}\text { Parameter } \\
\text { Estimate }\end{array}$ & Partial $R^{2}$ & $P$ \\
\hline Intercept & -402.56 & & 0.002 & -296.06 & & 0.025 \\
\hline IPAR & 0.757 & 0.49 & 0.001 & 1.41 & 0.43 & 0.00 \\
\hline RUE & 230.26 & 0.41 & 0.001 & 108.55 & 0.40 & 0.002 \\
\hline WD & -0.55 & 0.04 & 0.018 & -0.47 & 0.01 & 0.480 \\
\hline Model & & 0.94 & & & 0.83 & \\
\hline
\end{tabular}

$\mathrm{n}=15 ; \mathrm{WD}$, water deficit in $\mathrm{mm}$

Table 6. Multiple regression of phasic intercepted PAR (IPAR) components, over all radiation use efficiency (RUE) and water deficit (WD) to seed yield under full light, and phasic intercepted PAR components and over all RUE to seed yield under shade.

\begin{tabular}{|c|c|c|c|c|c|c|}
\hline \multirow[b]{2}{*}{ Variable } & \multicolumn{3}{|c|}{ Full Light } & \multicolumn{3}{|c|}{ Shade } \\
\hline & $\begin{array}{c}\text { Parameter } \\
\text { Estimate }\end{array}$ & Partial $R^{2}$ & $\mathrm{P}$ & $\begin{array}{c}\text { Parameter } \\
\text { Estimate }\end{array}$ & Partial $R^{2}$ & $\mathrm{P}$ \\
\hline Intercept & -422.20 & & $0.00 \overline{6}$ & -333.46 & & 0.003 \\
\hline IPARSF & 0.769 & 0.56 & 0.012 & 2.39 & 0.33 & 0.001 \\
\hline IPARF & 1.20 & 0.04 & 0.075 & 0.205 & 0.02 & 0.844 \\
\hline IPARV & 0.265 & $<0.01$ & 0.617 & 1.68 & 0.24 & 0.008 \\
\hline RUE & 239.77 & 0.30 & 0.001 & 109,54 & 0.29 & 0.001 \\
\hline WD & -0.56 & 0.04 & 0.027 & & & \\
\hline Model & & 0.90 & & & 0.86 & \\
\hline
\end{tabular}

$n=15$; the subscripts SF, F \& V denote the seed filling, flowering and vegetative phases, respectively 


\section{DISCUSSION}

The seed-filling phase was the most sensitive to water stress followed by the flowering and vegetative phases, respectively. Factors, such as inability to make further adjustments in canopy or seed yield components and the increased vulnerability of leaves to senescence under stress with increased age, could be some of the reasons for the susceptibility of the seed-filling phase. Plants may have a relatively better chance of recovery from drought during the flowering phase than during seed filling, in such indeterminate cultivars. The high sensitivity of the terminal developmental phase to stress is in agreement with the findings of Pandey et al. (1984), Walelign Worku et al. (2003) and Walelign Worku and Skjelvåg (2005). Pandey et al. (1984) suggested that indeterminate characteristics of some food legumes offer greater yield stability when short drought stresses occur during the vegetative or early reproductive phases than species or cultivars with determinate characteristics.

The presence of shade appeared to be advantageous in the developmental phases more sensitive to water stress and under more severe stress (Fig. 2) while it reduced seed yield both under optimum moisture supply and under the less sensitive phase of development for water stress. This may be attributed to the fact that the shade reduced the radiation load on the canopy and soil, reducing evapotranspiration and thereby avoiding a high degree of water stress. Similarly, in sorghum, Ludlow and Powles (1988) observed that shading water stressed plants for a seven day period increased grain yield of primary heads by 13 fold compared to unshaded plants. They said this was. due to improved soil moisture from shading. Similarly, Midmore et al. (1988) observed that shading has contributed to moisture conservation in potato. In wheat shading experiment Campbell et al. (1969) observed a yield advantage, under a $30 \%$ shade, when precipitation was low, while $50 \%$ shade was always detrimental. Another contributing factor for the improved yield could be reduced photoinhibition as a result of shading. Water stress predisposes leaves to photoinhibition with the magnitude depending on the level of irradiance and water stress (Björkman and Powles, 1984; Lu and Zhang, 1998). However, Ludlow and Powles (1988) suggested that the reduction of photoinhibition, by shading contributed little to the improved grain yield in sorghum. This may be partly attributed to the ability of sorghum to protect its leaves from high radiation dose under water stress by rolling them.

All the yield components were positively correlated with seed yield per unit area under both light regimes with pod number per plant accounting for the larger percentage of the variation. Pod number on branches was greatly reduced under shade due to the decreased number and size of branches. Though insufficient, the load on the main stem was enlarged and seed size and seed number per pod was increased to compensate for this. Thus, yield losses from shading might be associated with reduction in the number and size of branches (data not shown). In wheat, preanthesis shading reduced number of grains per unit area on tillers more than it did on main stems (Slafer et al., 1994).

Considering total LAD, drought during seed filling was the most important followed by that during the flowering phase. This indicated that leaf area reduction from early water stress was recovered when plants were relieved of the stress during the later phases. This could be attributed to the indeterminate growth habit of the cultivar. The trend in total intercepted radiation reflected that of the variation in total $\mathrm{LAD}$, in general. Accordingly, terminal drought has made the largest impact on light interception. The influence of flowering phase water stress was smaller on LAD and intercepted PAR. The low impact on intercepted PAR may also be explained by the nature of the relationship between fractional light interception and LAI in that differences in interception are rather small at that level of LAI.

The mean RUE value obtained was $1.85 \mathrm{~g} \mathrm{DM} \mathrm{MJ}^{-1}$ PAR under the 'non limiting' condition (well watered and full light throughout). Comparable figures were reported for pigeon pea (Nam et al., 1998), groundnut (Stirling, 1990) and cowpea, mung bean and soybean (Muchow et al., 1993). The relationship between dry matter and intercepted radiation has been usually represented by a linear function (Muchow, 1985; Nam et al., 1998; Sinclair and Muchow, 1999). The curvilinear relationship indicating lower RUE values during the early developmental phase, in this experiment, may be attributed to low night temperatures. For instance, Bell et al. (1992) suggested that reduced $\mathrm{CO}_{2}$ assimilation following cool nights could be a possible reason for the reduced RUE in groundnuts. The other reason could be that the proportion of leaves that were light saturated would be higher at lower leaf area indices making RUE values lower. During later developmental phases radiation is 
attenuated down through the canopy. Also, the level of radiation was slightly higher during the early phase of plant development.

Radiation use efficiertcy was reduced by drought especially under the high light intensity as it was also reported in pigeon pea (Nam et al., 1998), in five-grain legumes (Muchow, 1985) and in barley (Jamieson et al., 1995). Loss of leaf photosynthesis through increased stomatal resistance could be the main mechanism for RUE reduction due to moderate water stress. For instance, Tilahun Amede and Schubert (2003) observed a 25\% drop in dry matter production due to mild drought because of reduced photosynthesis rate as a result of significant reduction in stomatal conductance, in common bean. The result substantiates the observation of Nam et al. (1998) who suggested that water stress decreases dry matter production through reducing RUE in addition to its effect on limiting LAD. The absence of a large difference in RUE under shade between moist and dry treatments may be partly attributed to the low level of stress that was developed in the shade due to the reduced radiation. Moreover, the impact from non-stomatal limitation of photosynthesis, like photoinhibition, might be more pronounced under high light intensity.

The plants under the shade showed considerably higher RUE values, a mean of $2.37 \mathrm{~g} \mathrm{DM} \mathrm{MJ}^{-1}$ PAR. Similarly, Stirling et al. (1990) under $46 \%$ shade in groundnut and Horie and Sakuratani (1985) under $50 \%$ shade in rice have reported a substantial increase of RUE under shade. Also in a milletgroundnut intercrop mixture, Marshall and Willey (1983) have shown the higher RUE value of groundnut in the mixture as one of the mechanisms responsible for the improved efficiency of the system. Shade increases the proportion of diffuse radiation because of scattering of direct beam radiation (Allen, 1975). Being more uniformly distributed this diffuse radiation improves the contribution of lower leaves (Sinclair $e l$ al., 1992). The light saturation irradiance of conmon bean is around 690-1075 $\mu \mathrm{mol} \mathrm{m} \mathrm{m}^{-2} \mathrm{~s}^{-1}$ on a single leaf basis. Irradiance reached $2000 \mu \mathrm{mol} \mathrm{m} \mathrm{s}^{-1}$ during the off season for about three hours each day making the upper leaves over saturated and assimilating at low RUE.

Intercepted PAR followed by RUE explained the largest variation in sëed yield under both light regimes. However, water stress also made some contribution under full light. It was indicated that the effect of water stress was primarily expressed through reduced light interception and low RUE
(Table 5 and Fig. 3). Reduced light interception was the result of decreased $L A D$, which in turn was caused by loss of leaf area and shortened growth duration. Thus, the extra contribution from water stress can be taken, as an effect that was accounted for neither by intercepted PAR nor by RUE.

Comparison of light intercepted in the three different phases showed that the seed-filling phase had the largest influence on seed yield. This could be taken as the reflection of the higher impact of water stress on leaf area duration during this phase. Also, the importance of intercepted PAR during seed filling may show the significance of current assimilate supply irr determining seed yield levels in common bean. Most legumes seem unable to retranslocate dry matter stored previously (Squire, 1990). Comparable relationships were observed in soybean (Egli, 1997) and faba bean (De Costa et al., 1997). Ljght intercepted during flowering did not make a significant contribution in explaining the variation in sced yield. This may be because of the lower impact of water stress on LAD at this phase. Also, differences in intercepted PAR are small at higher values of LAI, which was the case during flowering. The influence of intercepted light, during the vegetative phase, was significant only under shade. This may be attributed to low canopy development after the flowering phase because of restricted branching, in the shade.

The results from this experiment have shown that the most susceptible developmental phase for moderate water stress was the seed filling phase followed by the flowering phase, for this indeterminate cultivar. This may suggest that when a short drought is anticipated during the vegetative or early flowering, indeterminate cultivars may be recommended. Loss of seed yield under shading was related to low pod number on branches, which in turn was the: result of reduced branch number and size. It might, therefore, be beneficial to select for cultivars that would carry more pods on their main stem for intercropping production systems. The results indicated that shading could be advantageous in maintaining yield by delaying the onset of severe water stress especially during the more susceptible phonological phases and prolonged water limitation. Loss of intercepted PAR during the seed filling was the most important factor accounting for the greater part of variation in seed yield, under both light regimes. Thus, leaf area maintenance under terminal drought could be a useful trait for screening resistant cultivars. The higher radiation 
and water use efficiencies obtained under shading and the relatively better terminal leaf area maintenance under the shade could be some of the mechanisms contributing to the increased efficiency of intercropping systems involving legumes. Further studies involving the same magnitude of stress under both full light and shade would help to gain insight into the other mechanisins and to develop models describing seed yield under different water and light levels.

\section{REFERENCES}

1. Allen, L.H. (1975). Shade-cloth microclimate of soybeans. Agron. J. 67:175-181.

2. Allen, R.G., Pereira, L.S., Raes, D. and Smith, M. (1998). Crop evapotranspiration: Guide lines for computing crop water requirements. $F A O$ Irrigation and Drainage Paper 56, FAO, Rome, Italy. pp. 1-297.

3. Asfaw Negassa and Abubaker Mussa (1990). Socioeconomic assessment of haricot bean production in Wollega region. In: IAR Proceedings on Haricot Bean Research in Ethiopia. pp. 19-23. Addis Ababa, Ethiopia.

4. Bell, M.J., Wright, G.C. and Hammer, G.L. (1992). Night temperature effects on radiation use efficiency in peanut. Crop Sci. 32:1329-1335.

5. Björkman, O. and Powles, S.B. (1984). Inhibition of photosynthetic reactions under water stress: Interaction with light level. Planta. 161:490-504.

6. Campbell, C.A., Pelton, W.L. and Nielsen, K.F. (1969). Influence of solar radiation and soil moisture on growth and yield of Chinook wheat. Can. J. Plant Sci. 49:685-699.

7. De Costa, W.A.J.M., Dennett, M.D., Ratnaweera, U. and Nyalemegbe, K. (1997). Effects of different water regimes on field-grown determinate and indeterminate faba bean (Vicia faba L.). II. Yield, yield components and harvest index. Field Crops Res. 52:169-178.

8. De Souza, P.I., Egli, D.B. and Bruening, W.P. (1997). Water stress during seed filling and leaf senescence in soybean. Agron. J. 89:807-812.

9. Ehdaie, B. and Waines, G. (1993). Variation in water use efficiency and its components in wheat: I. Well-watered pot experiment. Crop Sci. 33:294299.

10. Egli, D.B. (1997). Cultivar maturity and response of soybean to shade stress during seed filling. Field Crops Res. 52:1-8.

11. Gifford, R.M., Thorne, J.H., Hitz, W.D. and Giaquinta, R.T. (1984). Crop productivity and photoassimilate partitioning. Science. 225:801-808.
12. Horie, T. and Sakuratani, T. (1985). Studies on cropweather relationship model in rice. I. Relation between absorbed solar radiation by the crop and the dry matter production. I. Agr. Met. 40:331-342.

13. Jamieson, P.D., Martin, R.J., Francis, G.S. and Wilson, D.R. (1995). Drought effects on biomass production and radiation use efficiency in barley. Field Crops Res. 43:77-86.

14. Lu, C.M. and Zhang, J.H. (1998). Effects of water stress on photosynthesis, chlorophyll a fluorescence and photoinhibition in wheat plants. Aust. J. Plant Physiol.p5:883-892.

15. Ludlow, M.M. and Powles, S.B. (1988). Effects of photoinhibition induced by water stress on growth and yield of grain sorghum. Aust. J. Plant Physiol. 15:179-194.

16. Marshall, B. and Willey, W. (1983). Radiation interception and growth in an intercrop of pearl millet/groundnut. Field Crops Res. 7:141-160.

17. Midmore, D.J., Roca, J. and Berrios, D. (1988). Potato (Solanum spp.) in the hot tropics. IV. Intercropping with maize and the influence of shade on potato microenvironment and crop growth. Field crops Res. 18:141-157.

18. Monteith, J.L. (1972). Solar radiation and productivity in tropical ecosystems. J. Applied Ecol. 9:747-766.

19. Muchow, R.C. (1985). An analysis of the effect of. water deficits on grain legumes grown in a semi-arid tropical entironment in terms of radiàtion interception and its efficiency of use. Field Crops Res. 11:309-323.

20. Muchow, R.C., Robertson, M.J. and Pengelly, B.C. (1993). Radiation use efficiency of soybean, mung bean and cowpea under different environmental conditions. Field Crops Res. 32:116.

21. Nam, N.H., Subbarao, G.V., Chauhan, Y.S. and Johansen, C. (1998). Importance of canopy attributes in determining dry matter accumulation of pigeon pea under contrasting. moisture regimes. Crop Sci. 38:955-961.

22. Pandey, R.K., Herrera, W.A. and Pendleton, J.W. (1984). Drought response of grain legumes under irrigation gradient I: Yield and yield components. Agron. J. 76:549-552.

23. Pidgeon, J.D. (1972). The measurement and prediction of available water capacity of ferrallitic soils in Uganda. J. Soil Sci. 23:430-441.

24. Shimelis W/Hawariat, Mitiku Haile and Wogayehu Bekele (1990). Haricot bean production system in Hararghe highlands. In: IAR Proceedings on Haricot Bean Research in Ethiopia. pp. 14-18. Addis Ababa, Ethiopia.

25. Sinclair, T.R. and Muchow, R.C. (1999). Radiation use efficiency. Adv. Agron. 65:215-265. 
26. Sinclair, T.R., Shiraiwa, T. and Hammer, G.L. (1992) Variation in crop radiation use efficiency with increased diffuse radiation. Crop Sci. 32:12811284.

27. Singh, S.P. (1995). Selection for water stress tolerance in interracial populations of common bean. Crop Sci. 35:118-124.

28. Slafer, G.A., Calderini, D. F., Miralles, D.J. and Dreccer, M.F. (1994). Preanthesis shading effects on the number of grains of three bread wheat cultivars of different potential number of grains. Field Crops Res. 36:31-39.

29. Squire, G.R. (1990). The Physiology of Tropical Crop Production. CAB Inter., Wallingford, pp. 49, 162.

30. Stirling, C.M., Williams, J.H., Black, C.R. and Ong, C.K. (1990). The effect of timing of shade on development, dry matter production and light use efficiency in groundnut (Arachis hypogaea L.) under field conditions. Aust. J. Agric. Res. 41:633-644.
31. Tenaw Workayehu and Yeshi Chiche (1990). Importance, production system and problems of haricot bean in the southern zone. In: IAR Proceedings on Haricot Bean Research in Ethiopia, pp. 8-13, Addis Ababa, Ethiopia.

32. Tilahun Aimede and Schubert, S. (2003). Mechanisms of drought resistance in grain legumes: II stomatal regulation and root growth. SINET: Ethiop. J. Sci. 26(2):137-144.

33. Walelign Worku, Skjelvåg, A.O. and Gislerød, H.R. (2003). Responses of common bean (Phaseolus vulgaris L.) to photosynthetic irradiance levels during three phenological phases. Agronomie: Agriculture and Environment 24:267-274.

34. Walelign Worku and Skjelvåg, A.O. (2005). Responses of haricot bean to moisture availability and two temperature regimes. Ethiop. J. Biol. Sci. 4(1):11-25.

35. Wortmann, C.S., Kirkby, R.A., Eledu, C.A. and Allen, D.J. (1998). Atlas of Common Bean (Phaseolus oulgaris L.) Production in Africa, pp. 7-41. 